\title{
Low Total Pathologic Complete Response (tpCR) Rate to Preoperative Chemotherapy in Patients with Invasive Lobular Carcinoma of Breast (ILC): Analysis of Subgroup of Three Phase II Trials
}

\author{
Parham Khosravi Shahi* \\ Professor de la Universidad Francisco de Vitoria, Facultativo Especialista en Oncología Médica, Servicio de Oncología Médica, Hospital General \\ Universitario Gregorio Marañón, Spain
}

Submission: July 15, 2019; Published: August 27, 2019

"Correspondence Author: Parham Khosravi Shahi, Professor de la Universidad Francisco de Vitoria, Facultativo Especialista en Oncología Médica, Servicio de Oncología Médica, Hospital General Universitario Gregorio Marañón, Madrid, Spain

Abstract

Background: Total pathologic complete response (tpCR; ypT0/is ypN0) after preoperative chemotherapy (PCT) is associated with better outcome in locally advanced breast cancers. However, the tpCR rate according to histology is not usually considered in trials.

Patients and Methods: Patients with invasive lobular breast carcinoma (ILC), including in 3 phase II trials (AT, ATX and TXH), were eligible. Expression of markers and clinical phenotypes $(\mathrm{CPh})$ were determined by immunohistochemistry. The primary end-point was tpCR rate in patients with ILC. Secondary end-points were breast conservation surgery rate (BCSR), event-free survival (EFS), and overall survival (OS).

Results: In the subgroup of patients with ILC ( $\mathrm{n}=16)$, median age was 50 years, $56.25 \%$ was premenopausal, median tumor size was $5 \mathrm{~cm}$, and $68.75 \%$ had clinically node involvement. Six patients (37.5\%) had clinical stage II and $10(62.5 \%)$ had clinical stage III. Hormone receptor positive disease was present in $93.75 \%$ of the patients, and median Ki-67 was $25 \%$. CPh were Luminal A-like in 37.5\%, Luminal B-like in 50\%, HER2-positive in $6.25 \%$ and triple negative in $6.25 \%$ of tumors. Only 1 patient $(6.25 \%)$ had a tpCR, and another patient had a pCR only in the breast. With a median follow-up of 146 months, median EFS was 120 months (95\% CI: 68-139), and median OS was not reached. Ten-year EFS and OS probability was $47 \%$ and $60 \%$, respectively. BCSR was only $12.5 \%$.

Conclusion: PCT in patients with ILC is associated with low tpCR rate, due to the majority of these patients have Luminal tumors with low chemo-sensitivity.

\section{Introduction}

Invasive lobular carcinoma (ILC) accounts for $10-15 \%$ of all breast cancers, and is associated with higher stage at diagnosis [1]. ILC tend to have more hormone receptor positive and HER2 receptor negative biological subtypes and less responsive to chemotherapy. Preoperative chemotherapy (PCT) is traditionally used in the treatment of patients with locally advanced breast cancer (LABC) in attempt to downstage disease and achieve breast conservation surgery (BCS) [2]. Total pathologic complete response in breast and nodes (tpCR; ypT0/is ypN0) after PCT is associated with better outcome. However, the pCR rate according to histology is not usually considered in trials.

\section{Patients and Methods}

\section{Patients and Eligibility Criteria}

We conducted an exploratory analysis of tpCR rate in the subgroup of patients with ILC of breast. Adult patients (>18 years of age) with histologically confirmed locally advanced or inflammatory ILC of breast, including in three phase II trials (AT, ATX and TXH), were eligible in this study [3]. Patients were treated with one of the following regimens of PCT, as previously reported: TXH (docetaxel, capecitabine and trastuzumab), ATX (doxorubicin, docetaxel, and capecitabine) or AT (doxorubicin 


\section{Cancer Therapy \& Oncology International Journal}

and docetaxel) [4,5]. Adjuvant Chemotherapy (CT), Radiotherapy (RT) and hormone-therapy (HT) were allowed after surgery. Expression of markers and clinical phenotypes $(\mathrm{CPh})$ were determined by immunohistochemistry before PCT. Patients were required to give written informed consent before inclusion in the trials [6]. The study protocols were approved by the institutional review board at each study center, and the study was conducted in accordance with the principles of the Declaration of Helsinki.

\section{Study end-points}

Primary end-point of the study was the tpCR rate, defined as no evidence of invasive cancer cells in either breast tissue and lymph nodes removed during surgery (ypT0/is ypN0), after PCT in the subgroup of patients with ILC. Secondary end-points were clinical response (CR) rate, BCS rate, pathologic tumor size, event-free survival (EFS) and overall survival (OS). EFS was defined as the time from the beginning of PCT until the date of the first occurrence of one of the following events: recurrence of ipsilateral breast tumor, recurrence of ipsilateral locoregional breast cancer, a distant disease recurrence, or death from any cause [7]. OS was defined as the time from the diagnosis of ILC of breast until death from any cause [8].

\section{Statistical Analysis}

Standard summary statistics for continuous variables were: median, range, standard deviation and/or 95\% confidence interval (95\% CI). Standard summary statistics for discrete variables were: count and proportion. Response rates were summarized by proportions. Survival estimations (EFS and OS) were calculated with Kaplan-Meier methods. The stata statistical program, version 14 (StataCorp. 2007. Stata Statistical Software: Release 14. College Station, TX: StataCorp LP) was used for all statistical analyses.

\section{Results}

\section{Patient Characteristics and pre- and Post-Surgical treatment}

Of 185 patients with LABC treated with PCT in the three trials (AT, ATX and TXH), 16 patients had ILC (8.65\%): 10 patients in the AT trial (62.5\%), 5 patients in ATX trial $(31.25 \%)$ and 1 patient in TXH trial $(6.25 \%)$. Patients with ILC were treated with a median of 4 cycles (range: $3-6$ ) of PCT. In this subgroup of patients, median age was 50 years (range: $38-66), 56.25 \%(n=9)$ was premenopausal, median tumor size was $5 \mathrm{~cm}$ (range: 3-6), and $68.75 \%(\mathrm{n}=11)$ had clinically node involvement. Six patients (37.5\%) had clinical stage II breast cancer and 10 (62.5\%) had clinical stage III. Hormone receptor positive disease was present in $93.75 \%(n=15)$ of the patients, only 1 patient had a HER2positive tumor (6.25\%) and median Ki-67 was 25\% (range: 5-70). CPh were Luminal A-like in $37.5 \%(\mathrm{n}=6)$, Luminal B-like in $50 \%(\mathrm{n}=8)$, HER2-positive in $6.25 \%(\mathrm{n}=1)$ and triple negative in $6.25 \%(n=1)$ of tumors (Table 1$)$.

Table 1: Baseline clinical and pathological characteristics of the study population $(n=16)$.

\begin{tabular}{|c|c|c|}
\hline Characteristics & $\mathbf{n}$ & $\%$ \\
\hline \multicolumn{3}{|c|}{ Menopausal Status } \\
\hline Premenopausal & 9 & 56.25 \\
\hline Postmenopausal & 7 & 43.75 \\
\hline \multicolumn{3}{|c|}{ Clinical T Stage } \\
\hline $\mathrm{T} 2$ & 4 & 25 \\
\hline T3 & 7 & 43.75 \\
\hline $\mathrm{T} 4$ & 5 & 31.25 \\
\hline \multicolumn{3}{|c|}{ Clinical N Stage } \\
\hline No & 5 & 31.25 \\
\hline $\mathrm{N}+$ & 11 & 68.75 \\
\hline \multicolumn{3}{|c|}{ Clinical Stage } \\
\hline IIA & 2 & 12.5 \\
\hline IIB & 4 & 25 \\
\hline IIIA & 3 & 18.75 \\
\hline IIIB & 4 & 25 \\
\hline IIIC & 3 & 18.75 \\
\hline \multicolumn{3}{|c|}{ Tumor Grade } \\
\hline II & 10 & 62.5 \\
\hline III & 6 & 37.5 \\
\hline \multicolumn{3}{|c|}{ Hormone Receptor Status } \\
\hline Positive & 15 & 93.75 \\
\hline Negative & 1 & 6.25 \\
\hline
\end{tabular}




\section{Cancer Therapy \& Oncology International Journal}

\begin{tabular}{|c|c|c|}
\hline HER2 status & \multicolumn{2}{|c|}{} \\
\hline Positive & 1 & 9.25 \\
\hline Negative & 15 & 3.75 \\
\hline & Clinical Phenotype & 57.5 \\
\hline Luminal A-like & 6 & 50 \\
\hline Luminal B-like & 8 & 6.25 \\
\hline Triple Negative & 1 & 6.25 \\
\hline
\end{tabular}

Ten patients (62.5\%) were treated with adjuvant CT, 4 patients (25\%) with CMF (cyclophosphamide, methotrexate, and fluorouracil) and 6 patients (37.5\%) with anthracycline and taxane-based CT (AT y ATX), with a median of 2 cycles (range: 1-2). One patient (6.25\%) with HER2-positive tumor was treated with adjuvant trastuzumab. Eleven patients (68.75\%) were treated with adjuvant RT, with a median dose of 50 Gy (IC 95\%: 41-60 Gy). Fifteen patients (93.75\%) with hormone receptor positive tumors were treated with HT, 8 patients (50\%) with tamoxifen and 7 patients $(43.75 \%)$ with an aromatase inhibitor (letrozole or anastrozole).

\section{Primary and Secondary end-points}

Of the 16 evaluable patients with ILC, only 1 patient (6.25\%) had a tpCR, this patient had a triple negative tumor. Another patient achieved a pCR only in the breast (pCR in the breast of $12.5 \%$; Table 2). The overall CR rate was $68.75 \%(11 / 16)$, with $12.5 \%(2 / 16)$ of clinical complete response and $56.25 \%$ $(9 / 16)$ of clinical partial response. One patient $(6.25 \%)$ had a progression during PCT. The BCS rate was only $12.5 \%(2 / 16)$, and the median pathologic tumor size after PCT, in the 15 patients without a tpCR, was $2.4 \mathrm{~cm}$ (IC 95\%: 0-3.3 cm) [9-11].

Table 2: Clinical and pathologic responses to preoperative chemotherapy $(n=16)$.

\begin{tabular}{|c|c|c|}
\hline Response & n & $\%$ \\
\hline \multicolumn{3}{|c|}{ Pathologic response (Primary endpoint) } \\
\hline Total pathologic complete response (breast \& nodes) & 1 & 6.25 \\
\hline Pathologic complete response only in the breast & 2 & 12.5 \\
\hline \multicolumn{3}{|c|}{ Clinical response (Secondary endpoint) } \\
\hline Overall clinical response & 11 & 68.75 \\
\hline Clinical complete response & 2 & 12.5 \\
\hline Clinical partial response & 9 & 56.25 \\
\hline Progression to preoperative chemotherapy & 1 & 6.25 \\
\hline
\end{tabular}

With a median follow-up of 146 months (95\% CI: 113179 months), median EFS was 120 months (95\% CI: 68-139 months). The EFS probability at 3 years, 5 years and 10 years was $60 \%, 53 \%$ and $47 \%$, respectively (Figure 1). Median OS in this subgroup of patients was not reached; and 3-year, 5-year and 10 -year OS probability was $80 \%, 67 \%$ and $60 \%$, respectively
(Figure 2). In this population, 50\% (8/16) of patients had an EFS event: 6 patients (37.5\%) had visceral metastasis as first recurrence, 1 patient $(6.25 \%)$ had only ipsilateral breast recurrence and 1 patient (6.25\%) had ipsilateral locorregional recurrence. Seven patients $(43.75 \%)$ had died due to tumor progression in the study.

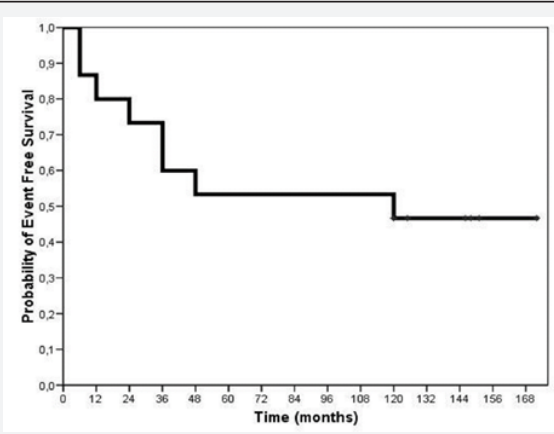

Figure 1: Enhanced computed tomographic scan.

In the subgroup of patients with locally advanced invasive lobular breast carcinoma treated with preoperative chemotherapy $(n=16)$, with a median follow-up of 146 months (95\% Cl: $113-179$ months), median EFS was 120 months (95\% Cl: 68-139 months); and 5-year and 10year EFS probability was $53 \%$ and $47 \%$, respectively. 


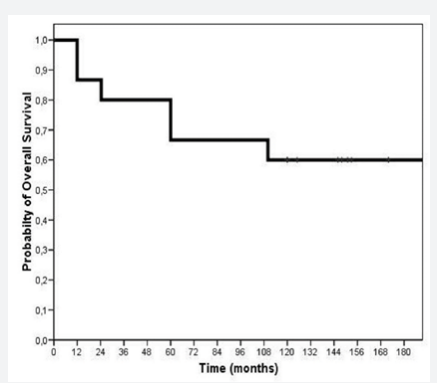

Figure 2: Kaplan-Meier Estimates of overall survival (OS).

In the subgroup of patients with locally advanced invasive lobular breast carcinoma treated with preoperative chemotherapy $(n=16)$, with a median follow-up of 146 months (95\% Cl: 113-179 months), median OS was not reached; and 5-year and 10-year OS probability was $67 \%$ and $60 \%$, respectively.

\section{Discussion}

The goal of PCT in breast cancer is to downsize tumor and nodal burden allowing for options of less aggressive surgical management converting the need for mastectomy or axillary lymph node dissection to lumpectomy or sentinel lymph node biopsy. As the use of PCT increases, it is important to evaluate which patient subgroups will derive most benefit from PCT. One must weigh the benefits and risks of giving systemic CT. While the goal of less aggressive surgery is a great option, the risk of giving CT to a tumor type not likely to respond to CT risks the side effects of overtreatment. In our study, tpCR rate in patients with locally advanced ILC of breast treated with PCT was low (tpCR of $6.25 \%$ ), and these patients had poor outcome with 10 year EFS and OS probability of only $47 \%$ and $60 \%$, respectively, despite the fact that they were treated with adjuvant CT $(62.5 \%)$, RT $(68.75 \%)$ and/or HT (93.75\%). In addition, only $12.5 \%$ of patients were undergone a BCS. Similar results in terms of BCS rate after PCT have been published in the literature.

Thus, PCT might not be a good treatment option in patients with locally advanced ILC of breast, because of the vast majority of these patients have Luminal A and B tumors. In fact, in our study hormone receptor positive disease was present in $93.75 \%$ of the patients, and $87.5 \%$ of patients had Luminal like tumors (37.5\% Luminal A-like and 50\% Luminal B-like). Moreover, the only patient with ILC who achieved a tpCR after PCT had a triple negative tumor. The results of our study is similar to previous studies, which have shown lower tpCR rates in patients with ILC compared to patients with invasive ductal breast carcinoma,

In conclusion, PCT in patients with ILC is associated with low tpCR rate, due to the majority of these patients have Luminal tumors with low chemo-sensitivity, and this strategy might be also associated with low BCS rates and poorer outcome.

\section{Conflict of Interest}

The authors declare that they have no conflict of interest.

\section{References}

1. Pestalozzi BC, Zahrieh D, Mallon E, Gusterson BA, Price KN et al. (2008) Distinct clinical and prognostic features of infiltrating lobular carcinoma of the breast: combined results of 15 International Breast Cancer Study Group clinical trials. J Clin Oncol 26(18): 3006-3014.

2. Sachelarie I, Grossbard ML, Chadha M, Feldman S, Ghesani M, et al. Primary systemic therapy of breast cancer. Oncologist 11(6): 574-589.

3. Cortazar P, Zhang L, Untch M, Mehta K, Costantino JP et al. (2014) Pathological complete response and long-term clinical benefit in breast cancer: the CTNeoBC pooled analysis. Lancet 384(9938): 164-172.

4. Manga GP, Shahi PK, Ureña MM, Pereira RQ, Plaza MI, et al. (2010) Phase II study of neoadjuvant treatment with doxorubicin, docetaxel, and capecitabine (ATX) in locally advanced or inflammatory breast cancer. Breast Cancer 17(3): 205-211.

5. Quiben R, Palomero MI, Cassinello J (1901) Doxorubicin combined with weekly docetaxel in locally advanced or inflammatory breast cancer (BC). J Clin Oncol 37: 1901.

6. Perez G, Khosravi-Shahi P, Izarzugaza Y (2009) Phase II study of neoadjuvant treatment with docetaxel, capecitabine, and trastuzumab in HER-2-positive locally advanced or inflammatory breast cancer: TXH trial. J Clin Oncol 27: e11581.

7. Coates AS, Winer EP, Goldhirsch A, Gelber RD, Gnant M, et al. (2015) Tailoring therapies-improving the management of early breast cancer: St Gallen International Expert Consensus on the Primary Therapy of Early Breast Cancer 2015. Ann Oncol 26(8): 1533-1546.

8. Truin W, Roumen RM, Siesling S, van der Heiden-van der Loo M, Duijm LE, et al. (2015) Patients with invasive lobular breast cancer are less likely to undergo breast-conserving surgery: a population based study in The Netherlands. Ann Surg Oncol 22(5): 1471-1478.

9. Petrelli F, Barni S (2013) Response to neoadjuvant chemotherapy in ductal compared to lobular carcinoma of the breast: a meta-analysis of published trials including 1,764 lobular breast cancer. Breast Cancer Res Treat 142(2): 227-235.

10. Truin W, Vugts G, Roumen RM, Maaskant-Braat AJ, Nieuwenhuijzen GA, et al. (2016) Differences in response and surgical management with neoadjuvant chemotherapy in invasive lobular versus ductal breast cancer. Ann Surg Oncol 23(1): 51-57.

11. Lips EH, Mukhtar RA, Yau C, de Ronde JJ, Livasy C, et al. (2012) Lobular histology and response to neoadjuvant chemotherapy in invasive breast cancer. Breast Cancer Res Treat 136(1): 35-43. 
This work is licensed under Creative Commons Attribution 4.0 License

DOI: 10.19080/CTOIJ.2019.14.555899
Your next submission with Juniper Publishers will reach you the below assets

- Quality Editorial service

- Swift Peer Review

- Reprints availability

- E-prints Service

- Manuscript Podcast for convenient understanding

- Global attainment for your research

- Manuscript accessibility in different formats

( Pdf, E-pub, Full Text, Audio)

- Unceasing customer service

Track the below URL for one-step submission https://juniperpublishers.com/online-submission.php 